\title{
On a productive dialogue between religion and science
}

\author{
ENN KASAK \\ University of Tartu (Estonia) \\ enn@kasak.ee \\ ORCID: 0000-0002-7185-2660
}

\author{
ANNE KULL \\ University of Tartu (Estonia) \\ anne.kull@ut.ee \\ ORCID: 0000-0001-5876-532X
}

\begin{abstract}
Searching for common ground in philosophy, science and theology, it seems to us that it would be reasonable to maintain the position of realistic pragmatism that Charles Sanders Peirce had called pragmaticism. In the pragmaticist manner, we typify the knowledge and select the types of knowledge that might be useful for understanding the problems that are of interest to us.

We pose a question of how it would be possible to obtain practically useful information about reality, first from the perspective of natural sciences, and then from that of theology; that is, to diversify the ways of knowledge and just maybe, to move toward a productive dialogue between science and religion.
\end{abstract}

Keywords: knowledge; Peirce; pragmaticism; realism; theology. 


\section{Introduction}

The secularisation of Western Europe, which seems to have culminated at the end of the twentieth century, has made science responsible for the questions that had traditionally belonged to the domain of religion (Midgley 1992). Maybe this is the necessity of avoiding existential issues that has directed ideologists of science to take a more conciliatory position towards religion than they did half a century ago. This may be one of the motivators for opening and continuing the dialogue between science and religion. In the last third of the twentieth century there was a resumption of interest in the dialogue between science and religion, and this dialogue quickly became one-sided. Even today the prevalent opinion is that the religions should "update themselves" and become synchronized with sciences; however, the sciences would also do well to acknowledge the importance of religions and recognize some of their values, but religions have nothing of consequence to add to science (Granten 2010). Scientists often seem to be restricted by what Thomas Nagel calls 'the fear of religion' but Nagel demonstrates neither hatred against religion nor the contestability or inadequacy of religious beliefs. Nagel claims that atheists have no bigger reason to fear the relationship between spirit and world than they do the fundamental and irreducible laws of physics (2003, 130-131). Theology can sometimes use some concepts, methods, and thoughts that are also applicable to science, but the fear of religion prevents scientists from comprehending that the discussion does not have to lead to a god, even though the customary patterns of discussion are far from traditional for the scientist. It may happen that if they are to engage in a productive discussion on existential issues, the sciences also need to synchronize with religions or theology and yet maintain their fundamental paradigm. Unlike the natural sciences, it is quite common to theology to treat everything as united and related as a result of their relationship with the root cause: the creator, or god. Religion binds what is close and far, and keeps open the possibility for a change of mind, self-transformation, and self-transcendence.

A dialogue is productive if it results in the discussants incorporating some theological metaphysical statements into the statements of natural 
sciences in a way that recognizes the conclusive statements from the point of view of scientific thought. A further objective would be to describe phenomena whose existence or non-existence can be proved by experiments accepted by the natural sciences. ${ }^{1}$ We deal with the issues of truth, reality and knowledge, as these overlap with the concerns of natural sciences, unlike other existential questions.

In seeking common ground in philosophy, science and theology, it would be reasonable to maintain the position of realistic pragmatism that Charles Sanders Peirce called pragmaticism (CP 5.414) $)^{2}$, to distinguish it from other forms of pragmatism. As the later form of pragmatism is better known, therefore, considering the position of Peirce, we emphasize that this one is not typical pragmatism. Moreover, pragmaticism is often regarded as one form of pragmatism. Yet as these two groups differ on the question of truth, we need to distinguish pragmatism from pragmaticism. In cases when these groups are better considered together, we use the term pragmat(ic)ism.

The structure of the article is as follows.

The following section determines what kind of knowledge could be related to the existential questions of truth, reality and knowledge and how it relates to the scientific knowledge, by using Ronald Dworkin's approach to community personified. Pierce's pragmaticistic approach allows us to typify and select the types of knowledge that might be useful for understanding the problems that are of interest to us.

The second section explores the investigation of reality, first from the perspective of the natural sciences and then from the perspective of theology. Theology refers here to a method, not to the doctrinal content of a particular denomination, and we are looking for a means of methodological communication between theology and science. Concerning reality, reality in the sense of 'real' (the real or really existent world that exists whether

This does not refer to the evidence for God but to phenomena that may be complicated to explore from the materialist point of view, such as free will and the intuitive perception of truth.

2 We use the common way of referring to The Collected Papers of Charles Sanders Peirce : CP, followed by the number of the section. CP: Peirce, Charles Sanders. 1994, edited by John Deely, Membra Ficte Disjecta: Electronic edition. 
it is observed or not), must be distinguished from a representation based on sensory perception ('world-environment'), whereas in a productive dialogue the question of difference, sameness, or overlap could be regarded as experimental rather than as speculative.

The third section searches for a way to reconcile achievements in science with theology. We ask how it would be possible to obtain practically useful information about reality as really existent, whereas the effectiveness of examination of reality may depend on how widely and synergistically all the knowledge available to humankind could be used.

The conclusion is that today a productive dialogue between science and theology is possible. This dialogue can also be productive from a scientific point of view, since it is possible to explore science nonscientifically but nevertheless in a way that is acceptable to scientists.

\section{On types of knowledge}

The standard model of knowledge claims that knowledge is justified true belief, wherein the subject bears knowledge, and the object of knowledge is a proposition. This definition was attacked when Edmund Gettier cited examples (Gettier's counterexamples) of beliefs that are true and also justified, but thinking of them as knowledge is counterintuitive (1963). After Gettier's criticism, definitions of knowledge have become more sophisticated and their complementing process appears to be continuing (Pritchard 2009). It is possible to weaken Gettier's criticism in terms of scientific knowledge, taking into account that scientific knowledge should be considered as collective knowledge. It is also important for the formation of scientists' individual knowledge, because while relying on collectively gained knowledge, a scientist participates in shaping collective knowledge.

Peirce emphasizes the importance of collective knowledge in science. He often seems to refer to the scientific community, as he discusses how the researchers working in parallel arrive at a certain truth (Anderson 1995, 19). Following the example of Dworkin, one can consider a group of persons (e.g., scientific community) who are competent in a certain field and who com- 
municate with each other as a community personified (1986, 167-168ff.). We look at the community personified as a unity or super person, indicated by Z . In addition, the object of knowledge, what is known, may not be expressible by the proposition. For example, knowing a paradox, which can be expressed by contradictory propositions, or even inexpressible knowledge, which - by making an attempt to express it - results in an inadequate expression that can still can be understood by a member of the community. For example, one mathematician can understand another even if the used expression has no content and is internally inconsistent, for instance the expression "the set of all sets” (Moore 1990, 191-192). Theology would need the ability to express the inexpressible when speaking about god.

Instead of speaking about the proposition, it would be more general to speak about the object of knowledge (o), which might be a proposition, but this object might be expressed in any other way, for example, as a paradox. Now we define the knowledge of the community personified using the pre-Gettierian scheme:

$Z$ knows that $o$ if and only if (i) $Z$ believes that $o$; (ii) the belief of $Z$ that $o$ is true; and (iii) the belief of $Z$ that $o$ is justified while $Z$ is a knowing supersubject (a community personified) and $o$ is an object of knowledge that may be a proposition.

Let us abbreviate it as z-knowledge - a super person Z's justified true belief (Kasak and Veede 2016). Experience demonstrates that communities of researchers in a field characteristically hold both specialist and general notions that do not usually require additional justification to the social group. The body of scientists can be viewed as personified communities both as a whole and in parts; scientific knowledge can be seen as the knowledge of a community.

The standard definition of knowledge may be implemented to the individual subject. If subject $S$ has immediate access to the content of the object of knowledge, for instance, if it is a personal perception of mind or thought constructions, then such knowledge could be called s-knowledge, and the standard model of knowledge seems quite an appropriate description.

Both s- and z-knowledge are based on the context, which may be partially or completely explicitly inexpressible. Kant distinguished the category or 
concept of understanding [Notio, Verstandesbegriff] from the idea or concept of reason [die Idee, oder der Vernunftbegriff] $(1968,326)^{3}$. Ideas do not bring immediate benefit to the applications of the experience of concept of understanding, but participate in creating for them a harmonising and regulatory background. Kant's concepts of understanding are indeed a priori, but are only meaningful when represented with objects of experience: they cannot be applied outside of that experience. Kant's ideas and categories are subjective and his approach to the issue of universals is similar to that of conceptualists. However, we are observing them from the position of realistic pragmatism or pragmaticism. What is real, exists whether it is perceived or not (CP 5.430). Peirce usually regards an idea as a concept (1878), but there may be something real in it, “... the idea does not belong to the soul, it is the soul, which belongs to the idea" (CP 1.216). Thinking may, of course, include inadequate or fictional concepts that do not concern the reality, though they are true in the sense that they are being thought of. Peirce calls these ideas erroneous, and the idea that Peirce says to be true, usually denotes something general, and it is real. Below, we will use a specific expression, i.e., "real ideas" for denoting these ideas. A real idea is capable of influencing its owner in a way that in the owner's thought it is represented as a conception (or idea in the sense that Peirce uses it).

Realists can talk about knowledge without subject. Karl Popper introduced the concept of the "third world," which embraces the objective content of thought (1968, 333-34). This made it possible to distinguish subjective knowledge from objective knowledge as belonging to the third world. The elements of the objective knowledge are human creations and therefore imperfect. According to Popper, they are similar to Frege's understanding of the objective content of thinking, and differ from Plato's ideas (Popper 1994, 108-09). But because of their objectivity they are not Kant's ideas or categories, whereas Popper also postulated the existence of the third world as independent from other worlds. Peirce's real ideas differ from Popper's by the fact that according to Peirce the real ideas are not a human creation

3 Kritik der reinen Vernunft, B 377/A 320. 
-- quite the opposite. Neither are these the ideas of Plato, because Peirce's ideas do not have to be perfect and unchanging (CP 6.13).

Knowledge can be distinguished on the basis of universality, such as factual knowledge, knowledge of universals (including the laws of nature), or even more general knowledge (Kant's ideas) that organize knowledge of categories and universals, and which may be formulated as principles. A realist tries to see behind ideas something existent, and many - or even most - scientists are realists. The knowledge of the Peirce's real ideas may be propositional or non-propositional and they can be distinguished on the basis of Kant. This is justified by the fact that Peirce's philosophy is influenced by Kant (see CP 4.2). Peirce has said that Kant's idea penetrates into the depths, where the daylight hardly reaches, and that Kant thinks quite correctly when he does not think clearly (1902, 209-10).

A realist would say that Kant's concept of understanding and the concept of reason should come from something real, not from the nature of thinking itself. Kant denies the existence of universals as things, but recognizes the universals as concepts that represent things. However, Kant is not a pure conceptualist, for conceptions themselves are not universal-only their use is (Oberst 2015). Kant's universals belong to the field of logic, not metaphysics. Kant thinks that human knowledge has two stems - logic and experience - that grow from a single root unknown to us $(1968,66)^{4}$. According to a realist, Kant's concept of reason could be perceptible, and the knowledge of it is termed $u$-knowledge ( $\mathrm{u}$ referring to universals), whereas this is propositional knowledge. Knowledge about objects that in Kant's view appear as ideas (concept of reason) are termed i-knowledge (i referring to Kant's ideas). I-knowledge could be the participation or involvement in the real ideas functioning outside of us. It is quite problematic if not impossible to express as propositional knowledge, but sometimes it can be expressed as principles or by paradoxes. Expressing i-knowledge as a principle is likewise problematic. It seems that it is necessary to differentiate i-knowledge from $\mathrm{u}$-knowledge, although the demarcation line between propositional $\mathrm{u}$-knowledge and non-propositional i-knowledge is blurry and changing.

4 Kritik der reinen Vernunft, B 30/A 16. 
Scientists should be characterized by their tendency to question their knowledge and beliefs. But i-knowledge places the scientist in an awkward position, because the ideas are extremely difficult to control by experiment. For instance, when the cosmological idea is formulated as a principle, it would be very difficult to verify the validity of some principles in the Universe as a whole. The metaphysical statements compiled based on i-knowledge can be involved in the same discussion with the scientific claims, however, using the habitual methodology, these claims are not scientifically verifiable, such as the cosmological principles of Giordano Bruno. However, i-knowledge can be beneficial for science. It seems that Peirce, when studying cosmology (and using his philosophically elaborate method) was quite successful in putting i-knowledge to use (Kasak and Veede 2016). The influential theoretical physicist Lee Smolin has recognized the main postulates, predictions and issues of Peirce's cosmology (2013, 125-29). Nobel laureate Steven Weinberg refutes doubts as if philosophy has nothing new or useful to say to physicists about reality, and cites Peirce's philosophy as a positive example $(2003,205)$.

The objective content of both $\mathrm{u}$-knowledge and i-knowledge can be treated without a subject (objective knowledge in Popper's sense), becoming aware of it can take place collectively (z-knowledge) or individually. The question arises about the veracity of such knowledge. In case of propositional knowledge, a realist, relying on the correspondence theory of truth, can say that the discussion of objects embraced by a proposition is successful when a proposition is true and unsuccessful when it is false. A pragmat(ic) ist will pay attention to whether the proposition could be pragmatically operable, i.e., if the proposition is true, then something in empirical or mental worlds is different when compared with the state of affairs if the proposition is false (James 1908, 142). Proposition and its truth value ought to be at least potentially operable, either for a person, a community personified or, in fact, any subject capable of understanding the contents of the proposition. Also, in case of i-knowledge, the object of knowledge should be at least potentially operable, although the description of it as a proposition is problematic. 
In solving the problems of artificial intelligence, any system can be postulated to be a carrier of knowledge, which can provide meanings for the signs (representation), and use these meanings purposefully. Peeter Lorents defined the element of knowledge as a consecutive pair <sign, significance> and this does not contain the subject in a manifest form, but like data that has to be on a carrier, the sign-significance relation must also have a carrier, which could be called a knower (2001). Knower masters the language, which determines the syntax of signs (representations) and semantics of significances. Significance, in turn, may be a sign for something else.

Following Peirce, we can say that representation (sign by Lorents) is a sign only if there is an object symbolized by this representation - there must be the object, representation and carrier of significance (CP 2.228). The object may belong to the physical, mental or fictional realm. A realist can define a realistic knowledge ( $r$-knowledge), which could be a consecutive triplet <object, representation (sign), significance (interpretant)>, in which an object in the real world would correspond to the token. The representation-significance relationship has to have a carrier (knower), but its existence can be just potential. Objective realist knowledge requires the (potential) existence of an interpretant of infinite power, whereas the knowledge of the interpretant of finite power may be incomplete. Realist science strives for $\mathrm{Z}$ being as powerful carrier of the relation of the object-representationsignificance as possible. If we assume the (potential or actual) existence of a carrier with an infinite power of knowledge relations, then perhaps there is not much difference in terms of objective knowledge, whether it is the world of the content of objective knowledge (Popper's World 3), or the scholastic view that real objective knowledge exists in the mind of God, or even elsewhere.

Concerning knowledge, we cannot bypass the problem of justification. ${ }^{5}$ In case of s-knowledge it would be natural to choose the internalist position as the subject must have immediate of access to the basis of her beliefs.

About justification of the beliefs that serve for a basis of knowledge, see e.g. Pritchard (2009). 
If there is no such direct access, then it seems that an internalist pragmaticist should choose a rather fundationalist position, whose beliefs are premised on the foundation. Realists have unfortunately no widely accepted mechanism that would say how the reality determines the justification. It is possible to postulate that the subject has an abnormal cognitive ability - the sense of truth - which tells the subject whether the object of knowledge is true or not; like the other senses, the sense of truth can deceive, but an experienced "observer of truth" is rarely mistaken, as any experienced observer. If a realist attempts to justify this postulate, a reference to Peirce can help her. But concerning the question of the possibility of immediate perception, Peirce seems to have had different positions. In some of his previous works, he seems to suggest that there is no immediate access to reality (1868), yet later he seems to recognize the power of immediate intuition. He calls such a method of direct perception of truth musement (1908, 93ff), and apparently it can also be interpreted in terms other than purely theological ones. Perhaps the issue of direct truth-observance emerges more in relation with objects of i-knowledge, whereas theology has studied some of these objects more often than science and Peirce himself categorises it among phenomena remaining outside the realm of science.

An externalist, specifically a reliabilist, will bind justification with reliability of the procedure of justification, and that is a procedure that results in true rather than false beliefs. Knowledge does not necessarily need justification for the reliabilist but it is necessary to obtain the beliefs in a reliable manner. Unfortunately, it is not clear how to test reliability externally. In science and social context, rather an internalist position is taken -anything that $\mathrm{Z}$ considers reliable is reliable. At the same time, however, there is an endeavour to bind knowledge with externalist type of justification, e.g., experiments that can give different results than expected, and change the procedures considered reliable and the content of reliable beliefs. Science is concerned mainly with verbally communicated knowledge, and reliability has been defined quite clearly in the case of the given Z. For example, in physics, reliable knowledge can be tested experimentally. Let 
us call empirically verifiable knowledge $e$-knowledge. This is experiential knowledge that can be justified by different means.

A pragmaticist perspective could use different types of knowledge, listed and briefly described below:

- $s$-knowledge: subject has immediate access to the content of the object of knowledge, e.g., personal perception via senses or a construct of thought

- $z$-knowledge: the subject of knowledge is community personified

- e-knowledge: empirically verifiable knowledge

- $r$-knowledge: realistic knowledge from the point of view of pragmaticism, a consecutive triplet <object, sign, significance>, in which an object in the real world corresponds to a sign

- u-knowledge: knowledge of universals as of real ideas, it can be seen as a special case of $r$-knowledge

- $i$-knowledge: participation or involvement in real ideas operating outside of us that are difficult to express as propositional knowledge; sometimes it can be expressed in principles or paradoxes; object of knowledge is manifested through the regularity or irregularity of other knowledge or non-conventional cognitive abilities (such as the sense of truth).

These presented types do not provide classification for the term knowledge, since the semantic fields of the specified terms overlap, and it is not obvious whether they cover the whole semantic field of the term 'knowledge'. Below we see that these are important distinctions. By using them, the dialogue between science and religion becomes more understandable for both sides, since it is clear what aspect of knowledge her conversation partner has in mind. Searching for overlaps in philosophy, science and theology, mainly u-knowledge and i-knowledge are under attention below.

\section{Ways of exploring the reality}

A pragmaticist, being a realist, may postulate the really existent or real or primarily existent, which exists whether it is observed or not. Regarding realism, there may arise a question of what me might call super-realism, where behind 
each reality there can be even more real reality. ${ }^{6}$ But at the same time, this is where pragmat(ic)ism draws the boundary at which the movement along the hierarchy of reality remains speculative, because the reality, which is not pragmatically operable, cannot be, according to the pragmat(ic)ist, the object of effective productive discussion. Pierce's real idea is pragmatically operable, because it is able to influence the subject. But the source of real ideas can be the subject of a meaningful discussion only if it is possible to notice its pragmatic operability, e.g., as an object of immediate perception or in a regulatory role regarding perception or thinking. If an object of knowing and believing accurately reflects the real relationship between real objects, then it is possible to talk about its trueness even then, when no subject nor society is aware of it. A pragmaticist can say that it is potentially possible to become aware of it because of operability. John Poinsot presented similar arguments in his discussion of the sign and the sign relationship as early as 1632 , when he said that for signifying in a reality it suffices to be a sign potentially $(1985,125-126)$.

It seems that when discussing pragmaticistically, it is possible to use harmoniously the terms "reality," "I myself," "we” (which may be community personified Z), and various types of knowing about all of it, while scientists should be interested in u-knowledge, and they should understand the importance of i-knowledge. The modern scientist tends to be a physicalist who thinks that the physical world described based on scientifically confirmed e-knowledge is the real world indeed, in which each person has a subjective representation and the communities might have still some intersubjective representations. Religion is a cultural phenomenon, which can help people

\footnotetext{
A realist may consider as real the material world, where a human being believes oneself to live, similar to what is considered as real by the natural scientists. But it is possible that this so-called world-environment is not primary: it might be generated by a certain primary reality that may be very different from the world-environment. In this case realist may consider the primary reality more real and the world-environment less real. Primary world can be e.g. a programme that creates the world-environment and beings inhabiting there as a computer simulation, see e.g. Bostrom (2003). And the world, where this computer programme works, can be created by even a more primary reality. The point of view, according to which there may appear behind each reality a "more real" reality, we are calling super-realism.
} 
to comprehend and cope with the world. Any community personified by this kind of scientific attitude may include both extreme physicalists and more liberal critical realists.

One should differentiate between two different kinds of experiences. Ordinary experiences occur in the course of daily life. However, birth and death, and mystical, religious or other unusual experiences are very difficult to align with naïve-realistic worldview based on materialism. We call these cardinal experiences. W. James considers religious experiences as real, and gives examples of how they transform a person's life. In other words, they are pragmatically operable (2002).

Cardinal experiences can lay the foundation for s-knowledge, which is not propositional, and not immediately communicative, but which can express the references that may be understandable for those with similar experiences. This could become z-knowledge for the community, which considers such experiences a reliable way of obtaining knowledge. From the point of view of the community of physicalists, s-knowledge, based on cardinal experiences, can be seen as irrelevant or inadequate, but with subjective value. Thus, a physicalist may postulate, for example, that all personal experiences that are not in accordance with physicalism are inadequate in the context of reality. In this case, s-knowledge of a person with her cardinal experience is only knowledge about that experience but this knowledge has nothing in common with other types of knowledge.

Science is based on the experience that a person is able to obtain knowledge via the five senses and their extensions. Using a rational analysis it discovers and formulates the rules that may be considered laws of nature. The regularities of thinking (logic) and of abstractions created by thinking power (mathematics) are treated separately. A scientific realist thinks that e- and u-knowledge from the field of natural sciences overlap at least partly with $r$-knowledge. For an instrumentalist perspective, these are merely convenient tools. A critical realist considers these to be the truth apprehensions that could not be accurate. Discussion on the scientifically unapproachable reality or the subject's innermost beliefs cannot be an object of a meaningful scientific debate. 
We formulate the approach to the issue of the reality from the s $\mathrm{c}$ i e n$\mathrm{t}$ i f i c p o in $\mathrm{t}$ o f v i e w: It is reasonable to talk about only such a reality, which can be studied by means of science. In a significant sense, reality is describable using matter and its properties. Direct knowledge about the reality is not achievable, and the knowledge mediated by the senses and thinking always turns out to be incomplete.

Scientific thinking could be characterized by considering the world as uniform and causal, non-dogmatic and having achieved certainty due to critical doubting. The traditional theological-religious way of thinking could be characterized by an understanding of a world as divided into accessible (in this world) and inaccessible (beyond it), criticism of this world and idealistic for the world beyond. According to this theological way of thinking or expression there exist two worlds -- this world (world-environment) and the world beyond - the latter being a bit more important and true than the former. The theological problems of this way of thinking occurred in the first centuries of Christianity: it was not clear how the two worlds were related to each other and how to express this relationship. Since Christianity is a religion that requires historicity and nature (because of the historical Jesus), we had to find a way to speak of about it using the available, but imperfect terms of Hellenistic philosophy. The term physis comes from physicalist philosophy. For centuries, Greek philosophy thought of being using terms like "thing, matter, and substance." The individual as such, spontaneity, freedom, personality and its history were not considered categories of philosophy. In other words, with the wisdom of hindsight we now know that the notion expressed by the term physis fails to denote personal and free God, neither nature, nor people. To alleviate this problem, in the fifth century the Councils of Ephesus and Chalkedon suggested the communicatio idiomatum: a peculiar event of the language, which regulates the transfer of the characteristics between Jesus and God - God's attributes (e.g., the Almighty, omniscience, cannot be transferred to Jesus) and about God, in turn, one cannot say anything except what is known from the life of historical Jesus. But Thomas Aquino, for example, suggested as a linguistic device the method of analogia entis (analogy of being). 
A pragmaticist can regard the world beyond as the primary reality. A creation of the world from this perspective can be seen as the process of how the primary reality generates the secondary world (world-environment). A naive-realist with ordinary experience would consider this secondary world as the real and only world. Both science and theology are still arguably inadequate for understanding of the reality, but perhaps we may use them together for understanding reality as we use our two imperfect feet for walking. Further, we approach theology on that note that what is said of God as the ultimate reality can be taken as valid about the primary reality. In this case the postulate of the existence of God as a particular being is being abandoned. A religious person might speak of having been created by God and the evolutionary process, a secular person expresses the same by claiming to have been created by the natural and historical process. As discussed above, objective realistic knowledge requires (potential) existence of an infinitely capable interpreter. When discussing such an interpreter, theological reasoning might be useful.

A theologian can consider adequate the knowledge obtained by a person in an unconventional manner, for example by means of revelation or insight. Some cardinal experiences can also occur through traditional cognitive ability, for example, I witness a miracle. Such knowledge can be i-knowledge, and is not adequately communicated. For example, a revelation is often a single, unique and personal phenomenon that cannot be shared with others directly. The means of communication are inherently communal, but there still remains a problem of adequacy of communication even if the revelation is communicated by the receiver. Even if the sense of truth accompanying the revelation confirms the infallibility of revelation, a sceptical "truth observer" might still have doubts. Like any sense, the sense of truth can deceive, and the source of revelation may be suspect. Religious institutions often assume the right to determine which miracles and revelations are true (of divine origin), and which are not, but sceptics will not acknowledge these institutions as validators of truth.

The theological point of view admits the existence of revelations and may recognize that miracles are possible. However, it differs from the 
sectarian understanding by the fact that theology observes such aspects of the revealed truths that are communicative. Like science, theology relies on rational analysis. In addition to dealing with human life and ethics, theology can also present the rules that seek to reflect the regularities in the objective world, whether it be understood as the world-environment or the primary reality. For instance, miracles can be confirmed by those who have borne witness, and a scientist may assume that the miracle needs a scientific explanation. Theology is not focused on the investigation of nature, but on directing human life, the course of which is determined by knowledge of the primary reality. Theology is concerned with the immediate knowledge of reality, but reality appears in particular in a mental and moral universe. The material universe is not a prevailing one. The development of knowledge is evolving towards understanding the content of the immediate perception of the reality and better communication of it. Although such a knowledge may not be propositional, an adequate communication within the framework of a community can, however, be possible. For it is sufficient if the speech refers to the personal experience shared by some members of the community.

We formulate an approach to the reality from the $\mathrm{th}$ e o $\mathrm{log}$ i c a $\mathrm{l}$ p o in t of vi e w: this world (world-environment) can and must be studied by the natural sciences, but the natural sciences can produce only indirect information about the reality. The true (primary) reality is inaccessible to the senses, but it can be immediately perceptible by the mind. The verbalization of knowledge obtained this way is always incomplete.

Those whose lives have been affected by cardinal experiences in conflict with physicalism, find it difficult to accept a scientific description of the reality. Some people do not agree with the ethics proceeding from the physicalist worldview. They may remark that physicalism also is a disputable position, with matter as a philosophical category, an abstraction and not experienced through the senses. But a description of the theological reality is not convincing to those who have had no conscious experience of the cardinal experience. Some people do not accept that God could affect their free will. Some people do not accept ethics based on the theological 
worldview, and nowadays it is easy for them to find atheistic ideologies that disprove God, because God cannot be experienced by the senses from without nor can the existence of God be proved. For these reasons it is possible to affirm the inadequacy of the theological world theory. Even when having cardinal experiences, one can embrace a dualistic approach to the world, according to which there exist separate immaterial and material entities; at the same time it is not obligatory to share with the theologians their faith. The cardinal experiences belong to a human life, even scientific research requires cardinal experiences (e.g., intuition). Explanations of such experiences also need context and grounding unless explanations are sceptically or nihilistically renounced.

A pragmaticist can ask whether there is something pragmatically operable in immediate knowledge about the primary reality. Some theological schools give an affirmative answer to this question. In this case, a natural scientist can ask whether this knowledge includes anything that can be typified as e-knowledge, or at least as i-knowledge. A pragmaticist who recognizes the cardinal experiences does not exclude the possibility of immediate knowledge and considers it possible that the primary reality may significantly differ from the world-environment. A pragmaticist can provide tools for how to look for rational assurances of existence and operation of such a primary reality, credible for the community of natural scientists. A pragmaticist cannot distinguish strictly separated from clearly defined science and religion, and then imagine them as something like countries at war. (This does not mean that the methodological reductionism is not useful for the specific research task).

For instance, reality can be understood by regularity, using u-knowledge or i-knowledge. If $\mathrm{i}$-knowledge is achievable as immediate knowledge, and it is accessible to any community personified, it is worthwhile to explore the possibilities of its experimental affirmation without becoming bound by physicalist or theological ideology. The other way is to use the violations of regularity - the reality may appear as phenomena described by the facts that are not in accordance with the orderly conduct of the world. This may be indicated by the relationship characterized as the teleologically 
directed regularity (miracle) or imperfection (déjà vu) between the reality and world-environment. As for scientific ideology, this could be a research object for the future science. As for theological ideology, this could be called miracles or deception, a research object for future theology. A pragmaticist may take seriously this rational method created by synergies in science and theology, which recognizes the possibility of immediate perception of truth. A pragmaticist may develop a rational way of perceiving reality, which can take advantage of the resources of both scientific and theological method, but may not be reducible to either of them. It seems that both methods are today still on a primitive and misleading level.

We can describe the approach to the reality from the $\mathrm{p} \mathrm{rag} \mathrm{m}$ a $\mathrm{t} i \mathrm{c}$ i $\mathrm{s} t$ p o in t of vi e w. The primary reality can be sensually inaccessible through ordinary experiences, but its existence and properties can be referred by the cardinal experiences and by the regularity or irregularity of the link between the reality and the world-environment. Direct and communicative knowledge about the reality may be possible, but the methods for describing remain to be developed.

\section{The possible synergy between science and theology in research of reality and of science itself}

In expert use of language, such as philosophy, theology, or science, the conscious textual knowledge is of special importance and in science they are subjected to verification. But unconscious contextual knowledge will remain free from criticism. This creates a paradox in which unperceived knowledge is sometimes more certain than perceived knowledge. It is difficult to give up or to question a belief that you do not perceive. Like everyone else, scientists are not often aware of their beliefs; many of them are religious (or parareligious or quasi-religious) (Kasak 2011). Similarly, theologians are not always aware of the sources of their knowledge, which may very well be science, pseudoscience or parascience.

Science is a social form of activity, which for a long time was considered possible to be analysed only by science. No wonder that the "new priestly 
class" reserved all authority to judge knowledges and ideas to itself. Wittgenstein noted that the meaning of the world must be located outside of the world $(2002,86)^{7}$ and the significance of a system is located outside of that system. The significance of science can also be looked outside of science. For example, the philosophy of science analyses the science using the non-scientific means. It seems that science can be studied by using theology, religious studies and anthropology of religion.

Each research specialty poses its basic questions from a perspective. For example, religion can be researched from the perspectives of biological, sociological, psychological, and philosophical knowledge. Each new perspective may add useful insights. The same applies also in science. Approaching science via research methods for religious studies we might ask in which way and to what extent the religious or other beliefs, practices and institutions that serve for a basis of worldview observed in science differ from the beliefs, practices and institutions functioning in other fields. A study could be made of whether there are similarities or overlapping or universal phenomena in science and religions, or whether there exist things that the majority of the religious, and/or scientific communities believe. A question might be posed about what kind of theological relationship occurs between the disciplines or between science and social context, or science and the natural environment.

Science has grown out of theology and the two have become separated as the connection between science and truth has been broken. This has resulted in a progressive profit-oriented attitude to research policy, research funding and the ideology of science. This attitude has begun to produce scientists who no longer believe in science as a means of perceiving truth, and this way of thinking is reflected in the public environment. Religious studies and anthropology of religion are studying what is observable and public - this means that their interest is not directed to the things that are located in people's heads or hearts (and definitely not what takes place in the institutions). These disciplines deal mainly with comparative and

Tractatus Logico-Philosophicus, 6.41 
transcultural aspects of religion. But they cannot resolve the methodological problems of truth and wisdom concerning behaviour in the observed phenomena. A more traditional theology would be helpful here.

Theology today has often put on the disguise of science (on ideological or quasi-religious reasons) but there is at least one significant difference between science and theology. Science does not recognize the possibility of immediate perception of truth, or more precisely, although recognized, it is not considered good style. Theologies recognize the possibility that there is truth, it can be rationally incomprehensible, but it is still perceptible and therefore also researchable and describable. A scientist who knows about the philosophy of science generally dares to speak about the proximity of the truth, whatever it means.

Theology is controversial as a form of knowledge and imagination, especially today. It has a unique history and traditions of practice. It is often believed, for example, that theology is done in churches only or in the best case, there is added theology done in the universities or divinity schools. However, theology is practiced wherever somebody tries to answer questions about religious or inter-religious phenomena that deal with the universe in its depth. If in science, wisdom is related only to empirical facts, and the expansion of the sense of wisdom is suspicious, then theology can naturally regard wisdom in a much broader sense. A theologian, since 1991 the Regius Professor of Divinity at the University of Cambridge, David F. Ford said, "Wisdom (although it is a difficult concept with different meanings and analogies in different traditions) is probably the best understood and least controversial term that can be used on theology. Wisdom involves describing, understanding, explication, knowledge and decision-making, not only about the empirical facts, but also in connection with values, norms and beliefs that shape life of individuals, communities and institutions" $(2005,61)$. Theology looks for wisdom in connection to the questions of meaning, truth, beauty and tradition, the issues that shape human life and that people talk about in their everyday colloquial conversations. But the colloquial terms can cautiously be converged to the terminology used by theology, as well as to those terms, which may denote a religious experience. 
Perhaps we need theology outside of religious institutions and Western academic circles. This may add a new understanding of science and some phenomena. We may discover, for example, that science lost something important when it parted ways with theology. Perhaps this loss becomes more evident on the clear demarcation line between the modern science and "old-fashioned" theology.

A theological (religious) approach to science means that science is researched as a phenomenon, whose real objectives cannot always be described rationally, some of them (the pursuit of truth) are similar to the pursuit of God and recognition of foolishness is similar to the confession of a sin. Science must be studied from the theological point of view to describe the aspects of research (as human activity), cannot be described in a scientific way but whose existence must be acknowledged and rationally dealt with if we want research to maintain the heuristic power that it has had for some time and if research is to continue to meet the societal expectations that we have of science. Science that falls short of these expectations is called "bad science." Religion that does not meet the expectation of improving the quality of life is called "bad religion."

There is a tendency to promote the abandonment of science as an alternative for bad science and to use the abandonment of religion as an alternative for bad religion. The long-term consequences of such choices may be unclear, but it seems that abandonment of the intellectual achievements of humankind will not solve its problems, but only help to conceal them. In order to identify and describe bad science, metaphysics or religion/theology, an effective and unconventional, out-of-the-system point of view and dialogue are needed. A productive dialogue, in addition to recognition, will help to explain in the freshest way what the meaning of science, theology/ religion and metaphysics could be for humankind, and in the course of the dialogue it is possible to seek the meaning of a system outside of that system.

One of the further objectives of a productive dialogue would be to describe the phenomena whose existence or non-existence can be verified experimentally by science and the development of the ideology of these experiments. This question deserves further and longer consideration. It 
seems that here a pragmaticist point of view, developed in the course of a dialogue between science and theology and metaphysics, would be of value.

\section{Conclusion}

A productive dialogue between science and theology is possible, or more accurately, underway, but it should be openly acknowledged, and important questions and answers should be clearly formulated. Humankind already seems to possess the means for achieving immediate and future objectives of such a dialogue, but there is a lack of understanding of how to do it. Immaterialism should not be the object of ridicule. The scientific and religious imaginations may have parted their ways but they must share the same basic refusal to rest content with what we know. Willingness to travel to an unknown destination of the truth beyond the visible and material is not irrational, even if it may need non-rational for verification. The sense of truth and sense of participation in the world should not be excluded. It may be that in order to describe the reality we need the contributions by both science and theology.

The preceding text is not meant to approve of scepticism, irrationalism and mysticism as they are usually understood. Our goal is to diversify the ways of rational cognition, to explore and learn to use consciously and in a structured way such ways of acquiring knowledge that are not reducible to the normal cognitive abilities and whose rationality is often seen as questionable. Perhaps in the future this way will allow us to rationalize what so far has tended to be irrational, as well as the part of the scientific creative process based on intuition and insight, and to imbue the mystical parts of theology with new meanings.

A theological (religious) approach to science means that science is researched as a phenomenon whose real objectives cannot always be described rationally; some of them (e.g., the pursuit of truth) are similar to the pursuit of God. This restless faith is not a cultural universal. In fact, the endorsement of the inevitability of the status quo is much more prevalent. The long-term consequences of abandoning the search for truth 
may be unclear, but concealment and denial are never helpful for solving the problems of humankind.

The dialogue between science and theology is productive from a theological point of view, since the world-environment in which the theologians live is most productively studied by the sciences. This dialogue can also be productive from a scientific point of view, since it is possible to explore science non-scientifically but nevertheless in a way that is acceptable to scientists.

\section{References}

Anderson, Douglas R. 1995. Strands of System: The Philosophy of Charles Peirce. West Lafayette, Indiana: Purdue University Press.

Bostrom, Nick. 2003. “Are You Living in a Computer Simulation?” Philosophical Quarterly 53 (211):243-255.

Dworkin, Ronald. 1986. Law's Empire. Cambridge, MA: Harvard University Press. Ford, David F. 2005. “Theology. “- In The Routledge Companion to the Study of Religion, edited by John. R. Hinnels, 61-79. London and New York: Routledge. 61.

Gettier, Edmund L. 1963. “Is Justified True Belief Knowledge?” Analysis 23 (6):121-23. Granten, Eva-Lotta. 2010. "How Scientific Knowledge Changes Theology - A Case Study from Original Sin.” In How Do We Know? Understanding in science and Theology, edited by Dirk Evers, Antje Jackelen and Taede A. Smeades, 95-104. London: T \& T Clark International.

James, William. 1907.”Pragmatism's Conception of Truth.” The Journal of Philosophy, Psychology and Scientific Methods 4 (6):141- 55.

James, William. 2002. The Varieties of Religious Experience: A Study in Human Nature. Centenary edition, London and New York: Routledge.

Kant, Immanuel. 1968. Werke in zwölf Bänden. III. Kritik der reinen Vernunft I, Frankfurt am Main: Suhrkamp.

Kasak, Enn. 2011. “Unperceived Civil Religion in Science.” Problemos 80:94-106.

Kasak, Enn and Veede, Raul. 2016. "Understanding Knowledge through the Example of C. S. Peirce's Cosmology.” Acta Baltica Historiae et Philosophiae Scientiarum $4(2): 69-87$.

Lorents, Peeter. 2001. "Formalization of data and knowledge based on the fundamental notation-denotation relation.” In International Conference on Artificial 
Intelligence (IC-AI'2001) - Conference Proceedings, 1297-1301. CSREA Press, vol. III.

Midgley, Mary. 1992. Science as Salvation. London and New York: Routledge.

Moore, Adrian William. 1990. The Infinity. London \& New York: Routledge.

Nagel, Thomas. 2003. The Last Word. Oxford: Oxford University Press.

Oberst, Michael. 2015. "Kant on Universals." History of Philosophy Quarterly, 32(4): 335-352.

Peirce, Charles Sanders. 1868. "Questions concerning Certain Faculties Claimed for Man.” The Journal of Speculative Philosophy 2:103-114.

Peirce, Charles Sanders. 1878. "How to Make Our Ideas Clear.” Popular Science Monthly 12: 286-302.

Peirce, Charles Sanders. 1902. “Paulsen's Kant.” The Nation 75, 209-11.

Peirce, Charles Sanders. 1908. “A Neglected Argument for the Reality of God.” The Hibbert Journal 7:90-112.

Peirce, Charles Sanders. 1994. The Collected Papers of Charles Sanders Peirce, edited by John Deely, Membra Ficte Disjecta: Electronic edition. (In text: CP).

Poinsot, John. 1985. Tractatus de Signis: The Semiotic of John Poinsot, (Interpretive Arrangement by J. N. Deely). Berkeley, Los Angeles and London: University of California Press.

Popper, Karl Raimund. 1968. “Epistemology Without a Knowing Subject.” In Logic, Methodology and Philosophy of Science III, edited by Bob Van Rootselaar and Johan F. Staal, 333-373. Amsterdam: North-Holland Publishing Company.

Popper, Karl Raimund. 1994. Objective Knowledge: An Evolutionary Approach. Oxford: Clarendon Press.

Pritchard, Duncan. 2009. Knowledge. London: Palgrave Macmillan.

Smolin, Lee. 2013. Time Reborn. Boston, New York: Houghton Mifflin Harcourt.

Weinberg, Steven. 2003. Facing Up: Science and Its Cultural Adversaries. Cambridge, MA., London: Harvard University Press.

Wittgenstein, Ludwig. 2002. Tractatus Logico-Philosophicus. London and New York: Routledge. 